\title{
Noncontact three-dimensional evaluation of surface alterations and wear in NiTi endodontic instruments
}

\author{
Fabiano Guerra FERREIRA(a) \\ Igor Bastos BARBOSA(a) \\ Pantaleo SCELZA(a) \\ Marcello Bulhões MONTAGNANA ${ }^{(b)}$ \\ Daniel RUSSANO(c) \\ John NEFF(c) \\ Miriam Zaccaro SCELZA ${ }^{(a)}$
}

(a) Universidade Federal Fluminense - UFF,

Department of Endodontics, Niteroi, RJ, Brazil.

(b)Taylor Hobson of Brazil, São Paulo, SP, Brazil.

(c)Zygo Corporation, Middlefield,

$\mathrm{CT}$, United States of America.

Declaration of Interest: The authors certify that they have no commercial or associative interest that represents a conflict of interest in connection with the manuscript.

\section{Corresponding Author:}

Miriam Zaccaro Scelza

E-mail:scelza@terra.com.br

https://doi.org/10.1590/1807-3107BOR-2017.vol31.0074

Submitted: Apr 09, 2017

Accepted for publication: June 06, 2017

Last revision: July 07, 2017
Abstract: The aim of this study was to undertake a qualitative and quantitative assessment of nanoscale alterations and wear on the surfaces of nickel-titanium (NiTi) endodontic instruments, before and after use, through a high-resolution, noncontact, three-dimensional optical profiler, and to verify the accuracy of the evaluation method. Cutting blade surfaces of two different brands of NiTi endodontic instruments, Reciproc R25 ( $n=5)$ and WaveOne Primary $(n=5)$, were examined and compared before and after two uses in simulated root canals made in clear resin blocks. The analyses were performed on three-dimensional images which were obtained from surface areas measuring $211 \times 211 \mu \mathrm{m}$, located $3 \mathrm{~mm}$ from their tips. The quantitative evaluation of the samples was conducted before and after the first and second usage, by the recordings of three amplitude parameters. The data were subjected to statistical analysis at a 5\% level of significance. The results revealed statistically significant increases in the surface wear of both instruments groups after the second use. The presence of irregularities was found on the surface topography of all the instruments, before and after use. Regardless of the evaluation stage, most of the defects were observed in the WaveOne instruments. The three-dimensional technique was suitable and effective for the accurate investigation of the same surfaces of the instruments in different periods of time.

Keywords: Endodontics; Dental Materials; Microscopy; Optical Imaging.

\section{Introduction}

Physical properties of nickel-titanium (NiTi) endodontic instruments, including shape memory and high flexibility due to their super-elastic behavior, are important requirements for the preparation of curved and complex root canals. ${ }^{1}$

Nevertheless, a major concern with the clinical use of NiTi rotary instruments is that unexpected fractures can occur during root canal preparation, even in the absence of any previously visible defects or deformations on the instrument surfaces. ${ }^{2,3}$

Improvements such as thermomechanical treatments, changes in the chemical properties and manufacturing process of the alloy, and different cross-sectional designs have been used to increase the resistance to fatigue and fracture of NiTi instruments. ${ }^{4}$ These characteristics 
are incorporated in the Reciproc ${ }^{\circledast}$ (VDW, Munich, Germany) and WaveOne ${ }^{\circledR}$ (Dentsply Maillefer, Ballaigues, Switzerland) endodontic files systems which are made of a special thermomechanically processed nickel-titanium alloy (M-Wire) with improved mechanical properties. ${ }^{5}$ Moreover, these instruments are operated under reciprocating motion, ${ }^{6}$ which is reported to extend the lifespan of NiTi instruments, compared to conventional continuous rotation. ${ }^{7,8}$ The association between reciprocating motion and M-Wire alloy significantly improves the fatigue resistance of NiTi files, consequently reducing the risk of instrument fracture within the root canal. ${ }^{9}$

However, cumulative metal fatigue in NiTi instruments still remains a matter of concern. ${ }^{10}$ It has been reported that the rate of fatigue development from defects in NiTi alloys is higher than for other metal alloys with similar resistance. ${ }^{11}$ An additional problem is that the manufacturing process of $\mathrm{NiTi}$ instruments can cause surface defects such as scratches, transitional angles, microcavities, and debris that can lead to instrument fracture. ${ }^{12,13}$ Such defects can create stress areas associated with crack initiation and propagation, accelerating fatigue and leading to an irreversible mechanism to the material failure. ${ }^{14,15}$

The surface characteristics of new and used NiTi instruments have been previously evaluated. ${ }^{16,17}$ Scanning electron microscopy (SEM) has been widely employed for qualitative assessment of changes in the surface topography of the instruments. ${ }^{18}$ However, its inability to quantitatively evaluate surface alterations, leads to a subjective analysis. ${ }^{19}$ Furthermore, SEM analysis is performed under a "constructed bi-dimensional photograph image". ${ }^{20}$ Otherwise, atomic force microscopy (AFM) has been proposed to three-dimensionally assess the instrument surfaces by the analysis of nanoscale high-resolution images. ${ }^{21}$ Nonetheless, AFM analysis can only be applied to small and ultra-flat areas at any given time (up to around $20 \mu \mathrm{m} \times 20 \mu \mathrm{m}$ ), which precludes the mapping of large surface areas. ${ }^{22}$

Noncontact three-dimensional optical profilometry has recently emerged as an accurate method for the evaluation of the surfaces of NiTi instruments, providing nanoscale data by means of high-resolution three-dimensional images. ${ }^{8,23}$ This technique enables repeated measurements of same surfaces, independent of their magnification or type, whether flat, curved, stepped, rough, or smooth. ${ }^{22}$

Given the influence of surface defects on fatigue and failure of NiTi instruments, the purpose of the present work was to qualitatively and quantitatively evaluate and compare the wear on the cutting blade surfaces of reciprocating instruments before and after two-times usage in simulated root canals through a noncontact three-dimensional optical profilometry analysis. The null hypothesis tested is that there would be no significant differences, in terms of surface alterations and wear, on the topography of two different brands of NiTi rotary instruments after simulated clinical use in curved canals in resin blocks.

\section{Methodology}

\section{Sample selection}

For the study, a sample of NiTi reciprocating instruments (Reciproc and WaveOne, with ISO tip size 25 and 0.08 taper in the apical $3 \mathrm{~mm}$ ), obtained from different lots, were randomly separated into two groups of five instruments: Group RP (for Reciproc instruments) and Group WO (for WaveOne instruments). The specimens were first examined using an optical stereomicroscope with 10x magnification to observe any visible deformation, which was adopted as the exclusion criteria for the sample selection.

\section{Testing protocol}

The instruments were tested in simulated root canals, $19 \mathrm{~mm}$ in length and with $40^{\circ}$ angle of curvature, in clear resin blocks (Dentsply Maillefer, Ballaigues, Switzerland). All the instruments were tested for two times, and a new simulated root canal was used for each test. A calibrated operator performed all the in vitro instrumentations. Initially, a glide path was obtained using a size $10 \mathrm{~K}$-file (Dentsply Maillefer, Ballaigues, Switzerland) to reach the full working length (WL) of the simulated canal. Then, a standardized protocol was stablished to make the canal preparation procedure repeatable and comparable for all the reciprocating instruments. The method included the use of a total of ten in-and-out pecking motions to prepare, sequentially, each canal portion (coronal, middle and apical) until reaching the WL. All the instruments 
were activated with a 6:1 reduction handpiece (Sirona Dental Systems GmbH, Bensheim, Germany) powered by a torque-controlled motor (Silver Reciproc; VDW, Munich, Germany), using the preset Reciproc ALL program for the Reciproc instruments and the preset WaveOne ALL program for the WaveOne instruments. After each stage of the sequential instrumentation, the simulated canals were irrigated with $2.5 \mathrm{~mL}$ of $2.5 \% \mathrm{NaOCl}$, and the instruments were cleaned with gauze soaked in similar solution, in order to simulate clinical conditions.

\section{Measurement procedure}

A standardized procedure was employed to ensure the precision of the analysis of the same cutting blade surface area of the instruments at different times, according to Ferreira et al. ${ }^{8}$ Firstly, a number 5 dental explorer (Duflex, Rio de Janeiro, Brazil) was used to make a perforation in the silicone rubber stop that had been glued with LoctiteSuper-bonder adhesive (Henkel Ltda., São Paulo, Brazil) to the shaft portion of the instrument nearest to the handle section. The instrument handle was then fixed to a holder attached to the base of the motorized table. The measurement areas were then defined by first positioning the autofocus lenses of the equipment over the perforation, denoted point 0 . The image of the perforation displayed in the center of the computer screen was used to record the numerical values for the $\mathrm{x}, \mathrm{y}$, and $\mathrm{z}$ coordinates of the moving table, for each sample individually, to enable repeatable positioning, maximizing the accuracy of the measurements. From point 0 , the motorized table was then moved transversely forward to reach the tip of the instrument, and then moved back $3 \mathrm{~mm}$ in order to obtain the reading for the area at the cutting blade of the instrument. All measurements were performed in three dimensions for areas of $211 \times 211 \mu \mathrm{m}$, before and after the instruments usage for two times.

Comparison of the images generated at $\mathrm{T} 0$ and after the first (T1) and second (T2) tests confirmed that the sample positioning could be repeated with a high degree of accuracy (Figures 1 and 2).

\section{Surface evaluation}

The surface areas of the endodontic instruments were analyzed by scanning white-light interferometry, before and after the tests, by using an advanced high-precision noncontact 3D optical surface profiler (NewView $^{\mathrm{TM}}$ 8300, Zygo Corporation, Middlefield, CT, USA). The noncontact surface profiling technique is approved by the International Organization for Standardization (ISO/DIS 25178, Part 604) for the investigation of a broad range of materials surfaces.

\section{Quantitative analysis}

Quantitative evaluation of the morphological characteristics of the surfaces before and after the tests was performed by the analysis of the following field parameters (amplitude parameters) provided by the $\mathrm{Mx}^{\mathrm{TM}}$ software (Zygo Corporation, Middlefield, $\mathrm{CT}$, USA): $S a$, the average roughness observed over the measurement range; $S q$, the root mean square roughness; and, $S z$, the average height between peaks and valleys in the measurement field.
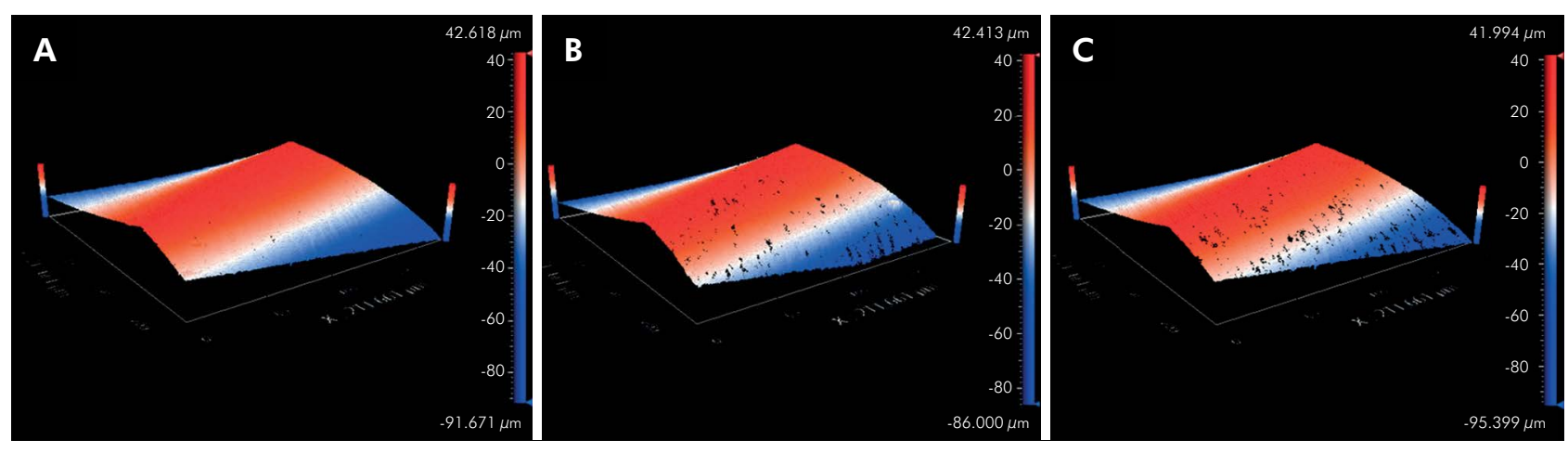

Figure 1. Three-dimensional high-resolution optical profilometry images of the cutting blade of a Reciproc instrument, before use (a) and after the first (b) and second (c) tests. 

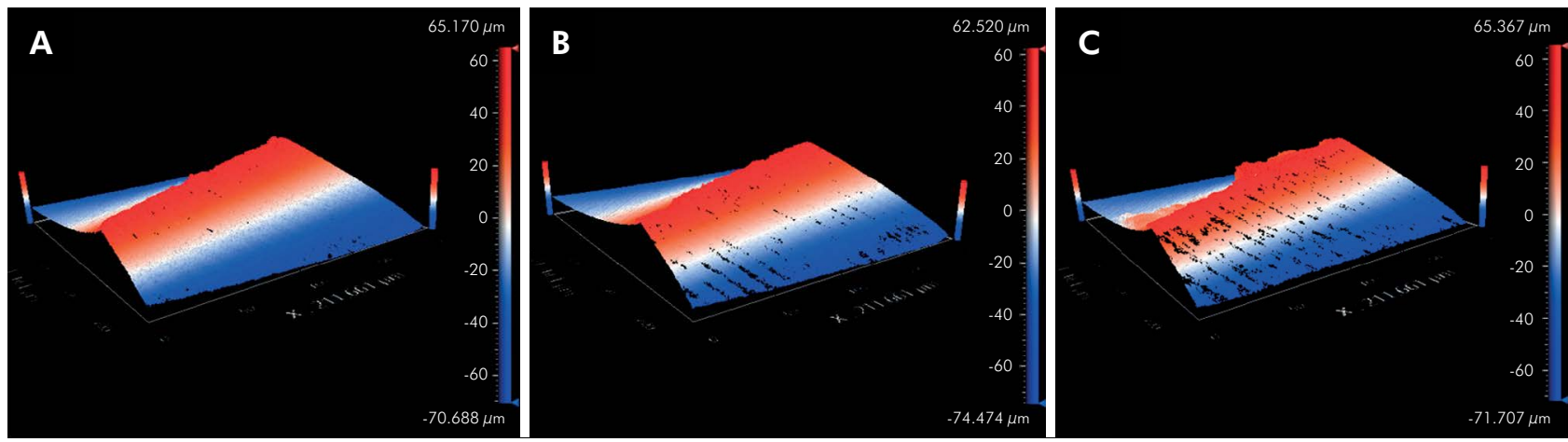

Figure 2. Three-dimensional high-resolution optical profilometry images of the cutting blade of a WaveOne instrument, before use (a) and after the first (b) and second (c) tests.

\section{Statistical analysis}

The data were submitted to statistical analysis to compare the values obtained for the parameters $\mathrm{Sa}$, $\mathrm{Sq}$, and Sz, before (T0) and after one (T1) and two (T2) uses of the Reciproc and WaveOne instruments. The data were first analyzed using the Friedman test $(p<0.05)$ to compare the characteristics of the instruments surfaces into their proper groups at the three stages of evaluation (T0, T1, and T2) and to determine the differences for all the parameters at each stage, individually. Subsequently, the data that showed statistically significant differences were subjected to the Dunn test $(\mathrm{p}<0.05)$ for multiple comparisons into the study groups. The Mann-Whitney test $(\mathrm{p}<0.05)$ was used to compare the groups RP and $\mathrm{WO}$, considering the numerical values obtained for the parameters $\mathrm{Sa}, \mathrm{Sq}$, and $\mathrm{Sz}$ in the evaluation stages T1-T0, T2-T0, and T2-T1.

\section{Results}

The data obtained for the groups RP and WO during the evaluation stages, $\mathrm{T} 0, \mathrm{~T} 1$ and $\mathrm{T} 2$, are displayed in Table 1 . Statistically significant differences $(p<0.05)$ were observed for the Reciproc and WaveOne instruments.

Considering the parameter $\mathrm{Sz}$, there were statistically significant $(\mathrm{p}<0.05)$ reductions in the amplitude between peaks and valleys caused by surface wear in the groups RP $(129.50 \rightarrow 118.76 \mu \mathrm{m}$, $\mathrm{p}=0.007)$ and $\mathrm{WO}(136.84 \rightarrow 125.64 \mu \mathrm{m}, \mathrm{p}=0.007)$ from the stages $\mathrm{T} 0$ to $\mathrm{T} 2$. The results revealed significant surface wear on the cutting blade surfaces of both instruments groups after the second test. However, the differences between the values obtained after the first (T1) and second (T2) tests revealed that wear was greater in the WaveOne instruments $(131.81 \rightarrow 115.98$ $\mu \mathrm{m})$, when compared to the Reciproc instruments $(121.19 \rightarrow 118.76 \mu \mathrm{m})$.

Analysis of the values obtained for the parameter Sa revealed a statistically significant difference from periods T1 to T2 for group WO $(26.34 \rightarrow 25.90$; $p=0.022)$. This reflected a decrease in the surface roughness patterns, with a reduction in the amplitude between valleys and peaks.

Comparisons of the values obtained for the parameters $\mathrm{Sa}, \mathrm{Sq}$, and $\mathrm{Sz}$ for the two groups of instruments at times T1-T0, T2-T0, and T2-T1 are presented in Table 2. No statistically significant differences were observed between the instrument groups ( $\mathrm{p}>0.05)$.

\section{Discussion}

In the present study, the same cutting blade surface areas of NiTi instruments were analyzed before and after two uses by using noncontact three-dimensional optical profilometry. The technique permits non-destructive and fast measurements, with no need for sample preparation and can be applied to a wide range of surface types with reflectivity ranging from $0.05 \%$ to $100 \%$. It has an extended scan range to measure the profile heights from $<1 \mathrm{~nm}$ up to $20,000 \mu \mathrm{m}$, with high vertical (z-axis) optical resolution $(0.01 \mathrm{~nm}), 0.4-0.6 \mu \mathrm{m}$ 
Table 1. Distribution of the values of the parameters Sa, Sq, and Sz for the groups Reciproc and WaveOne at times T0, T1, and T2.

\begin{tabular}{|c|c|c|c|c|c|c|c|c|}
\hline \multirow{3}{*}{$\begin{array}{l}\text { Groups and } \\
\text { variables }\end{array}$} & \multicolumn{8}{|c|}{ Evaluation Stages } \\
\hline & \multicolumn{3}{|c|}{ TO } & \multicolumn{2}{|r|}{$\mathrm{Tl}$} & \multicolumn{2}{|c|}{ T2 } & \multirow{2}{*}{$\mathrm{p}$-value } \\
\hline & Median $(\mu \mathrm{m})$ & Q1 & Q3 $(\mu \mathrm{m})$ & Median $(\mu \mathrm{m})$ & Q1 Q3 $(\mu \mathrm{m})$ & Median $(\mu \mathrm{m})$ & Q1 Q3 $(\mu \mathrm{m})$ & \\
\hline \multicolumn{9}{|l|}{ RE } \\
\hline $\mathrm{Sa}$ & 22.21 & 20.59 & 923.85 & 20.62 & 20.5122 .37 & 20.32 & 19.8421 .87 & 0.449 \\
\hline $\mathrm{Sq}$ & 27.25 & 24.40 & 028.23 & 24.51 & 24.2326 .40 & 23.92 & 23.4325 .55 & 0.074 \\
\hline $\mathrm{Sz}$ & 129.50 (a) & 123.87 & $7 \quad 131.89$ & 121.19 & $119.52 \quad 126.18$ & $118.76(b)$ & 117.85121 .70 & 0.007 \\
\hline \multicolumn{9}{|l|}{ wo } \\
\hline $\mathrm{Sa}$ & $26.61(a)$ & 24.05 & 527.08 & $26.34(a)$ & $25.90(b)$ & $25.90(b)$ & 23.6526 .39 & 0.022 \\
\hline $\mathrm{Sq}$ & 31.53 & 28.24 & 431.69 & 29.96 & 29.87 & 29.87 & 27.7530 .89 & 0.074 \\
\hline $\mathrm{Sz}$ & $136.84(a)$ & 121.98 & 8142.58 & 131.81 & $125.64(b)$ & $125.64(b)$ & 115.98134 .35 & 0.007 \\
\hline
\end{tabular}

${ }^{*}$ Medians with different letters are significantly different $(p<0.05)$.

Table 2. Comparison of groups Reciproc and WaveOne between times T1-TO, T2-TO and T2-T1 by the analysis of the parameters Sa, Sq and Sz.

\begin{tabular}{|c|c|c|c|c|c|c|}
\hline \multirow{3}{*}{ Times } & \multirow{3}{*}{ Variables } & \multicolumn{4}{|c|}{ Instrument } & \multirow{3}{*}{$\mathrm{p}$-value } \\
\hline & & \multicolumn{2}{|c|}{ Reciproc } & \multicolumn{2}{|c|}{ WaveOne } & \\
\hline & & Median $(\mu \mathrm{m})$ & Q1 Q3 $(\mu \mathrm{m})$ & Median $(\mu \mathrm{m})$ & Q1 Q3 $(\mu \mathrm{m})$ & \\
\hline \multirow{3}{*}{ T1-T0 } & $\mathrm{Sa}$ & 0.15 & -3.280 .86 & 0.34 & -0.471 .59 & 0.690 \\
\hline & $\mathrm{Sq}$ & 0.05 & -3.870 .46 & 0.22 & -1.031 .48 & 0.222 \\
\hline & $\mathrm{Sz}$ & -6.23 & $-8.47-2.63$ & -3.23 & $-4.14-0.74$ & 0.151 \\
\hline \multirow{3}{*}{ T2-T0 } & $\mathrm{Sa}$ & -0.88 & -3.830 .587 & -0.59 & $-0.85-0.30$ & 0.841 \\
\hline & $\mathrm{Sq}$ & -1.18 & $-4.62-0.12$ & -0.56 & $-1.57-0.27$ & 0.841 \\
\hline & $\mathrm{Sz}$ & -10.73 & $-11.37-4.83$ & -10.48 & $-13.22-1.37$ & 1.000 \\
\hline \multirow{3}{*}{ T2-T1 } & $\mathrm{Sa}$ & -0.37 & -1.280 .15 & -0.57 & $-2.11-0.35$ & 0.548 \\
\hline & $\mathrm{Sq}$ & -0.35 & -1.580 .19 & -0.74 & -2.610 .29 & 0.690 \\
\hline & $\mathrm{Sz}$ & -2.26 & $-5.66-0.57$ & -6.16 & $-9.63-0.63$ & 0.310 \\
\hline
\end{tabular}

Negative values indicate reductions of the numerical values obtained for parameters Sa, Sq and Sz when comparing the evaluation stages T1-T0, T2-T0 and T2-T1, whereas positive values denote increased values.

lateral resolution ( $\mathrm{x}$-and $\mathrm{y}$-axes), and a repeatability of $0.02 \mathrm{~nm}$ (Z-scanning) that enables reliable analysis to be made at different times. Measurement data obtained by using the $\mathrm{Mx}^{\mathrm{TM}}$ software tools permit the reproduction of surface characteristics, by the analysis of images constructed with over 1,900 million data points, and full quantification of the surface topography. The results demonstrated that the method provided accurate and reliable qualitative and quantitative analysis of the alterations on the surfaces of the reciprocating instruments before and after use.

Previous studies have recommended AFM as a valuable tool for three-dimensional investigation of the surfaces of NiTi instruments. ${ }^{21,24}$ Nevertheless, the very small scan size areas (up to $20 \times 20 \mu \mathrm{m}$ ) to be measured with the use of AFM make it difficult to determine how representative the obtained image may be of the surface as a whole..$^{25}$ On the other hand, the ability of interferometry to examine large scan areas can be used to evaluate the influence of scan size in determining surface roughness, as well as to provide a more comprehensive surface characterization. ${ }^{25}$ In the present research, large surface areas of the cutting blades of the instruments, measuring $211 \times 211 \mu \mathrm{m}$, were accurately analyzed, before and after two-times usage. The tests were performed in simulated canals manufactured in clear resin blocks. Such artificial canals enable the reproduction of the size and taper of the instrument, providing standardized testing conditions. ${ }^{26}$

This study was the first time that surface characteristics such as wear and roughness were statistically estimated for the analysis and comparison of cutting blade areas of reciprocating instruments before and after use. The data obtained by the quantitative analysis revealed significantly increased wear on the cutting blade surfaces of the Reciproc and WaveOne instruments after the second use, with substantial height 

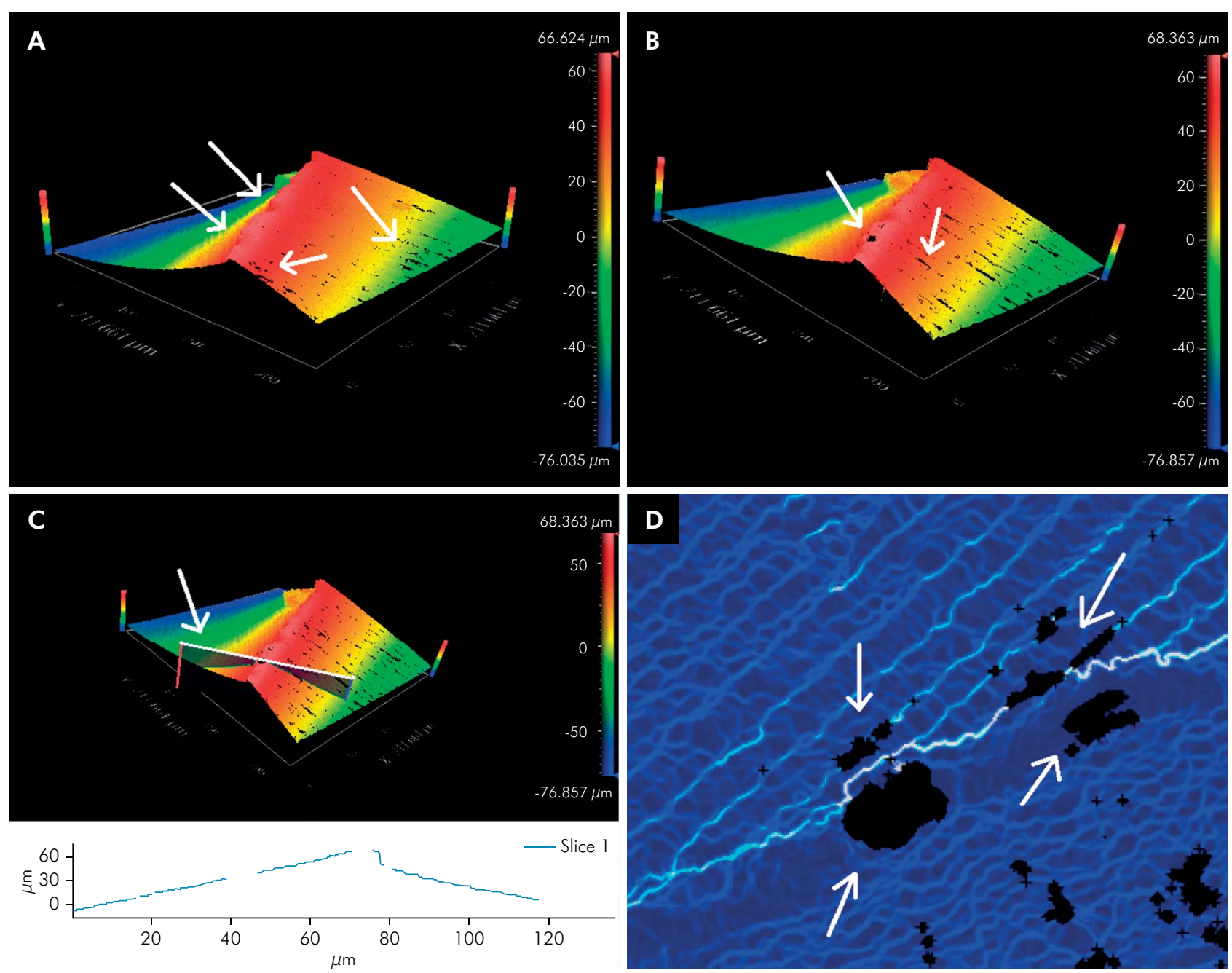

Figure 3. Optical profilometry characterization of irregularities (white arrows) on the cutting blade surface of a WaveOne instrument: (a) instrument surface showing milling marks, grooves, steps, pits and microvoids before use; (b) crack propagation after the second use; (c) transversal slice applied on the crater and crack propagation in the three-dimensional image of the surface with a profile graphic representation of the slice area showing disruptions on the analyzed surface; (d) propagation of cracks parallel to the local fluting orientation under connected pitted regions and an increased crater on the cutting edge border after the second use of the instrument.

loss on the measured surfaces. In addition, the WaveOne instruments showed a significant decrease in the surface roughness from the first to the second test, caused by the wear of the cutting blades. No statistical differences were found between the different instruments groups before and after the tests. A previous AFM analysis of three-dimensional images revealed an increased surface wear on the apical portions of Reciproc and WaveOne instruments after three usages. ${ }^{27}$ In agreement with the findings presented here, other AFM study pointed out no significant differences between these brands of NiTi files prior to use with an increase of surface irregularities in the WaveOne instruments after usage. ${ }^{28}$
On the qualitative analysis herein, surface irregularities were identified in both brands of instruments before and after use, especially in the WaveOne instruments. The Reciproc instruments showed, mostly, milling marks and little pits before use, with an increasing number of pits and microcavities being observed after the first and second usages (Figure 1a-c). Otherwise, in the WaveOne instruments, surface characteristics such as steps, grooves and little pits were shown even before use. After the first use, a great amount of microcracks, larger steps and grooves were observed, while after the second test, an increased number of the defects, 
mainly, grooves, steps, microcavities, microcracks and craters were clearly shown on the cutting blades surfaces of these instruments (Figure 2a-c). Recently, a SEM analysis of the cutting blades of Reciproc and WaveOne instruments revealed the presence of surface irregularities in both instruments before use and a greater presence of defects and deformities in the WaveOne instruments after use. ${ }^{17}$

Structural irregularities on the instrument surface have been reported to affect the NiTi instrument integrity during clinical use, making the file more liable to fracture. ${ }^{6}$ Oxide particles derived from the manufacturing process can act as nucleation sites for the formation of microvoids, leading to dimpled ruptures and subsequent instrument fracture. ${ }^{13,15,29}$ In the present study, crack propagation and connected pitted regions were clearly observed in both instruments after the second use, with a greater predominance in the WaveOne instruments (Figure 3a-d). In a previous SEM study, the propagation of cracks parallel to the local fluting orientation under connected pitted regions had been observed on the surfaces of used NiTi instruments. ${ }^{18}$

In the present research, each reciprocating instrument was tested for two times. The safe clinical use of the "single use" Reciproc and WaveOne instruments for shaping multi-rooted teeth has been discussed. According to Yamazaki-Arasaki et al., ${ }^{30}$ the single use of reciprocating instruments can actually refer to the use in three or four root canals of the same molar or of the same patient. Nevertheless, it was previously reported that although both instruments can be used in 3-4 root canals, the canals can be complex and tortuous, increasing fatigue. ${ }^{10}$ Hence, the adoption of single use practices may reduce but not eliminate the risk of metal failure.

The findings obtained here demonstrated that, compared to SEM and AFM techniques, the use of noncontact optical profilometry enabled greater precision in the qualitative and quantitative evaluation of surface characteristics of NiTi instruments before and after use. The accuracy and broad applicability of the technique make it a valuable tool for further investigations focusing on the effects of wear of endodontic instruments under different testing conditions.

\section{Conclusions}

The null hypothesis was rejected. The qualitative and quantitative analysis of Reciproc and WaveOne instruments revealed significantly increased wear on the surfaces of the cutting blades of both instruments after two tests in simulated root canals. Manufacturing imperfections were clearly observed for both instrument brands. Surface irregularities and defects were more predominant in the WaveOne instruments before or after use.

The method employing noncontact threedimensional optical profilometry provided accurate characterization of the surfaces of the NiTi instruments, with numerical description of the topography, turning reliable the evaluation and comparison of surface alterations under different conditions. The technique can be highlighted as a valuable tool for use in further investigations related to the influence of surface defects on the fracture of endodontic instruments during clinical use.

\section{Acknowledgements}

This work is based on a thesis submitted to the graduate faculty, Fluminense Federal University School of Dentistry, in partial fulfillment of the requirements for the Ph.D. degree.

Special thanks are due to Dr. David Melton, on behalf of Zygo Corporation, for kindly granting permission to use the three-dimensional optical profiler system.

\section{References}

1. Schäfer E, Oitzinger M. Cutting efficiency of five different types of rotary nickel-titanium instruments. J Endod. 2008;34(2):198-200. https://doi.org/10.1016/i.joen.2007.10.009
2. Sattapan B, Nervo GJ, Palamara JE, Messer HH. Defects in rotary nickel-titanium files after clinical use. J Endod. 2000;26(3):1615. https://doi.org/10.1097/00004770-200003000-00008 
Noncontact three-dimensional evaluation of surface alterations and wear in NiTi endodontic instruments

3. Martín B, Zelada G, Varela P, Bahillo JG, Magán F, Ahn $S$ et al. Factors influencing the fracture of nickel-titanium rotary instruments. Int Endod J. 2003;36(4):262-6. https://doi.org/10.1046/i.1365-2591.2003.00630.x

4. Gambarini G, Gergi R, Naaman A, Osta N, Al Sudani D. Cyclic fatigue analysis of twisted file rotary NiTi instruments used in reciprocating motion. Int Endod J. 2012;45(9):802-6. https://doi.org/10.1111/j.1365-2591.2012.02036.x

5. Gambarini G, Grande NM, Plotino G, Somma F, Garala M, De Luca M et al. Fatigue resistance of engine-driven rotary nickel-titanium instruments produced by new manufacturing methods. J Endod. 2008;34(8):1003-5. https://doi.org/10.1016/i.joen.2008.05.007

6. Kim HC, Kwak SW, Cheung GSP, Ko DH, Chung SM, Lee W. Cyclic fatigue and torsional resistance of two new nickel-titanium instruments used in reciprocation motion: reciproc versus WaveOne. J Endod. 2012;38(4):541-4. https://doi.org/10.1016/i.joen.2011.11.014

7. You SY, Bae KS, Baek SH, Kum KY, Shon WJ, Lee W. Lifespan of one nickel-titanium rotary file with reciprocating motion in curved root canals. J Endod. 2010;36(12):1991-4. https://doi.org/10.1016/j.joen.2010.08.040

8. Ferreira F, Barbosa I, Scelza P, Russano D, Neff J, Montagnana $M$, et al. A new method for the assessment of the surface topography of NiTi rotary instruments. Int Endod J. 2016. https://doi.org/10.1111/iej.12707

9. Pirani C, Ruggeri O, Cirulli PP, Pelliccioni GA, Gandolfi MG, Prati C. Metallurgical analysis and fatigue resistance of WaveOne and ProTaper nickeltitanium instruments. Odontology. 2014;102(2):211-6. https://doi.org/10.1007/s10266-013-0113-6

10. Plotino G, Grande NM, Testarelli L, Gambarini G. Cyclic fatigue of Reciproc and WaveOne reciprocating instruments. Int Endod J. 2012;45(7):614-8. https://doi.org/10.1111/j.1365-2591.2012.02015.x

11. Dauskardt RH, Duerig TW, Ritchie RO. Effect of in situ phase transformation on fatigue-crack propagation in Ti-Ni shape memory alloy. In Proceedings of $9^{\text {th }}$ Materials Research Society International Meeting on Advanced Materials, 1989, Pittsburgh, PA. p. 243-9.

12. Eggert $C$, Peters $O$, Barbakow F. Wear of nickel-titanium lightspeed instruments evaluated by scanning electron microscopy. J Endod. 1999;25(7):494-7. https://doi.org/10.1016/S0099-2399(99)80289-1

13. Kuhn G, Tavernier B, Jordan L. Influence of structure on nickel-titanium endodontic instruments failure. J Endod. 2001;27(8):516-20. https://doi.org/10.1097/00004770-200108000-00005

14. Alapati SB, Brantley WA, Svec TA, Powers JM, Mitchell JC. Scanning electron microscope observations of new and used nickel-titanium rotary files. J Endod. 2003;29(10):667-9. https://doi.org/10.1097/00004770-200310000-00014

15. Cheung GSP, Darvell BW. Fatigue testing of a NiTi rotary instrument. Part 2: fractographic analysis. Int Endod J. 2007;40(8):619-25.

https://doi.org/10.1111/j.1365-2591.2007.01256.x

16. Alapati SB, Brantley WA, lijima M, Clark WA, Kovarik L, Buie $C$ et al. Metallurgical characterization of a new nickel-titanium wire for rotary endodontic instruments. J Endod. 2009;35(11):1589-93. https://doi.org/10.1016/i.joen.2009.08.004

17. Hanan ARA, Meireles DA, Sponchiado Júnior EC, Hanan S, Kuga MC, Bonetti Filho I. Surface characteristics of reciprocating instruments before and after use: a SEM analysis. Braz Dent J. 2015;26(2):121-7. https://doi.org/10.1590/0103-6440201300208

18. Alapati SB, Brantley WA, Svec TA, Powers JM, Nusstein JM, Daehn GS. SEM observations of nickel-titanium rotary endodontic instruments that fractured during clinical Use. J Endod. 2005;31(1):40-3. https://doi.org/10.1097/01.DON.0000132301.87637.4A

19. Field J, Waterhouse P, German M. Quantifying and qualifying surface changes on dental hard tissues in vitro. J Dent. 2010;38(3):182-90. https://doi.org/10.1016/i.jdent.2010.01.002

20. Cazaux J. Recent developments and new strategies in scanning electron microscopy. J Microsc. 2005;217(P+ 1):16-35. https://doi.org/10.1111/i.0022-2720.2005.01414.x

21. Valois CR, Silva LP, Azevedo RB. Atomic force microscopy study of stainless-steel and nickel-titanium files. J Endod. 2005;31(12):882-5. https://doi.org/10.1097/01.don.0000164132.27285.2c

22. Ferreira FG, Nover DF, Silva NP, Garbui IU, Correr-Sobrinho L, Nover PRA. Qualitative and quantitative evaluation of human dental enamel after bracket debonding: a noncontact three-dimensional optical profilometry analysis. Clin Oral Investig. 2014;18(7):1853-64. https://doi.org/10.1007/s00784-013-1159-0

23. Lopes HP, Elias CN, Vieira MV, Vieira VT, de Souza LC, Dos Santos AL. Influence of Surface Roughness on the Fatigue Life of Nickel-Titanium Rotary Endodontic Instruments. J Endod. 2016;42(6):965-8. https://doi.org/10.1016/j.joen.2016.03.001

24. Fayyad DM, Mahran AH. Atomic force microscopic evaluation of nanostructure alterations of rotary NiTi instruments after immersion in irrigating solutions. Int Endod. 2014;47(6):567-73. https://doi.org/10.1111/iej.12189

25. Koyuncu I, Brant J, Lüttge A, Wiesner MR. A comparison of vertical scanning interferometry (VSI) and atomic force microscopy (AFM) for characterizing membrane surface topography. J Memb Sci. 2006;278(1-2):410-7. https://doi.org/10.1016/i.memsci.2005.11.039

26. Dummer PM, Alodeh MH, al-Omari MA. A method for the construction of simulated root canals in clear resin blocks. Int Endod J. 1991;24(2):63-6. https://doi.org/10.1111/j.1365-2591.1991.tb00809.x 
Ferreira FG, Barbosa IB, Scelza P, Montagnana MB, Russano D, Neff J et al.

27. Pirani C, Paolucci A, Ruggeri $O$, Bossù $M$, Polimeni $A$, Gatto MR et al. Wear and metallographic analysis of WaveOne and reciproc NiTi instruments before and after three uses in root canals. Scanning. 2014;36(5):517-25. https://doi.org/10.1002/sca.21150

28. Fatma Y, Ozgur U. Evaluation of surface topography changes in three NiTi file systems using rotary and reciprocal motion: an atomic force microscopy study. Microsc Res Tech. 2014;77(3):177-82. https://doi.org/10.1002/jemt.22325
29. Scelza P, Harry D, Silva LE, Barbosa IB, Scelza MZ.

A comparison of two reciprocating instruments using bending stress and cyclic fatigue tests. Braz Oral Res. 2015;29(1):1-7. https://doi.org/10.1590/1807-3107BOR-2015.vol29.0107

30. Yamazaki-Arasaki A, Cabrales R, Santos M, Kleine B, Prokopowitsch I. Topography of four different endodontic rotary systems, before and after being used for the 12th time. Microsc Res Tech. 2012;75(1):97-102. https://doi.org/10.1002/jemt.21021 